\title{
Effect of Aqueous Extracts of Bitter Leaf Powder on the Corrosion Inhibition of Al-Si Alloy in 0.5 M Caustic Soda Solution
}

\author{
F. A. Ayeni ${ }^{1 *}$, I. A. Madugu ${ }^{1}$, P. Sukop ${ }^{1}$, A. P. Ihom $^{1}$, O. O. Alabi ${ }^{1}$, R. Okara ${ }^{1}$, \\ M. Abdulwahab ${ }^{2}$ \\ ${ }^{1}$ National Metallurgical Development Centre, Jos, Nigeria \\ ${ }^{2}$ Department of Metallurgical and Materials Engineering, Ahmadu Bello University, Zaria, Nigeria \\ Email: *ayeflo@yahoo.com
}

Received January 23, 2012; revised February 29, 2012; accepted March 27, 2012

\begin{abstract}
The effect of bitter leaf (Vernonia amygdalina) extract as an inhibitor for aluminium silicon alloy in $0.5 \mathrm{M}$ solution of caustic soda using weight loss method has been investigated. The alloy of composition $9 \% \mathrm{Si}$ and $91 \% \mathrm{Al}$ was sand cast at the Foundry Shop of the National Metallurgical Development Centre, Jos, Nigeria. The cast alloy was cut and machined to corrosion coupons and immersed into $0.5 \mathrm{M} \mathrm{NaOH}$ solution containing varying inhibitor concentrations $(0.1 \%$, $0.2 \%, 0.3 \%, 0.5 \% \mathrm{v} / \mathrm{v}$ ) within a period of fifteen days. From the result, it was found that the adsorption of Vernonia amygdalina reduced the corrosion rate of this group of alloy in the alkaline medium. The inhibitive action of this plant extract was explained using inhibition efficiency and degree of surface coverage. The most suitable inhibitor concentration was found to be $0.5 \%$ with inhibition efficiency of $87 \%$. The mechanism of inhibition is by physical adsorption and the adsorbed molecules of the inhibitor lies on the surface of the alloy blocking the active corrosion sites on the alloy, hence, giving the alloy a higher corrosion resistance in the studied environment.
\end{abstract}

Keywords: Vernonia amygdalina; Adsorption; Inhibition Efficiency; Surface Coverage

\section{Introduction}

Corrosion of metals/alloys, which can be defined as the deterioration or disintegration of materials due to their reaction with the environment, has continued to receive attention in the technological world. Corrosion Scientists are relentless in seeking better and more efficient ways of combating the corrosion of metals/alloys. Aluminium and its alloys are widely used in engineering applications; these include, structural, domestic, transportation and electrical transmission lines. Due to the availability, moderate cost and relatively low resistance to corrosion, conductivity and other properties of this metal and its alloys, improving the corrosion resistance of these alloys by inhibiting the working environment is worth studying [1].

One of the ways of combating corrosion is the addition of inhibitors to the corroding environment. Inhibitors tend to ameliorate the destructive behavior of an aggressive environment. There are different types of inhibitors, which are organic and inorganic. Corrosion inhibitors are widely used in industry to prevent or reduce corrosion rate of metals in alkaline, acidic media and industrial

${ }^{*}$ Corresponding author. processes such as acid pickling and cleaning of refinery equipment, oil well acidizing and acid descaling [1]. The action of inhibitors is always associated with changes in the state of the surface being protected due to adsorption or formation of poorly soluble compounds with metal cations. Such compounds decrease the area of active metal surface and/or increase the corrosion energy [2]. The adsorption of the inhibitors unto the metal/alloy surfaces retards the cathodic or anodic electrochemical processes that accompany corrosion of the metal/alloy [2,3].

Studies have shown that the efficiency of inhibition is related to the amount of adsorbed inhibitor on the metal surface [4]. The inhibitor after adsorption may form a surface film that acts as a physical barrier restricting the diffusion of ions/molecules to or from the metal/alloy surface and may prevent the metal atoms from participating in either the anodic or cathodic reactions of corrosion $[5,6]$.

The use of plant extracts as organic inhibitors for the corrosion of metals/alloys, has gained very wide interest among researchers in recent time [7-9]. In the search for more environmentally friendly and readily available inhibitors, researchers have reported the use of local plants 
such as Vernonia amygdalina [10] and neem leaf [11]. In very many cases, the corrosion inhibitive effect of some plants extracts has been attributed to the presence of tannin in their chemical constituents [12]. Avwiri and Igho, (2003) reported the inhibition efficiency of Vernonia amygdalina (bitterleaf) on the corrosion of aluminium alloy in $0.1 \mathrm{M} \mathrm{HCl}$ and $0.1 \mathrm{M} \mathrm{HNO}_{3}$ to be $49.5 \%$ and $72.5 \%$ respectively.

The use of naturally occurring plant extracts as inhibitors is particularly interesting and economical because they are cheap, non-toxic, ecological friendly and poses little or no threat to the environment $[2,13]$.

Vernonia amygdalina commonly called bitter leaf is non-toxic plant available in every part of Nigeria; it is mainly used locally as vegetable in soup because of its medicinal efficacy. Hence, this research is aimed at the possibility of using this non-toxic plant as a corrosion inhibitor of Al-Si alloy in 0.5 Molar caustic soda solution, since it has been reported that aluminium based alloys have low corrosion resistance in alkaline media $[1,14]$.

\section{Materials and Methods}

\subsection{Materials}

The aluminium alloy used in this research was sand cast at the foundry shop of the National Metallurgical Development Centre, Jos, Nigeria. Its composition was 9\% Si and $91 \%$ Al. Other materials used include: extract from Vernonia amygdalina and ethanol.

\section{Equipment}

The equipment used for the work were, Setra electronic digital weighing balance model BL-410S, steel brush, beakers, measuring cylinder, thread, retort stand and easy way digital PH meter model PHS-25.

\subsection{Methods}

\subsubsection{Determination of the Chemical Composition of Plant Extracts}

The chemical composition of the plant extract was determined at the Chemistry Department Laboratory of Ahmadu Bello University, Zaria, Nigeria.

\subsubsection{Corrosion Testing}

After casting, the aluminium alloy was cut and machined to corrosion coupons (cylindrical shape) of dimension $1.5 \times 1 \mathrm{~cm}$. fifteen coupons were produced for different concentration of inhibitor $(0.1 \%, 0.2 \%, 0.3 \%$ and $0.5 \%)$ in the $0.5 \mathrm{M} \mathrm{NaOH}$ solution and reference medium which was $0.5 \mathrm{M} \mathrm{NaOH}$ solution without inhibitor. The coupons were polished and degreased in absolute ethanol, dried, weighed and stored in desiccators. $0.5 \mathrm{M} \mathrm{NaOH}$ solutions containing the inhibitor of concentrations $0.1 \%$,
$0.2 \%, 0.3 \%$ and $0.5 \% \mathrm{v} / \mathrm{v}$ were prepared and the coupons immersed in these solutions. The weight loss of each coupon was determined at 5 days interval for 15 days.

Then the rate of corrosion, inhibition efficiency and degree of surface coverage were determined. The experiment was conducted at room temperature in the range of $26^{\circ} \mathrm{C}-30^{\circ} \mathrm{C}$.

\subsubsection{Determination of Corrosion Rate (mpy) and Inhibition Efficiency (\%)}

The weight loss was determined by finding the difference between initial and final weight of coupon after 5 days of immersion from the relationships [1].

$$
W=W_{o}-W_{f}
$$

where $W$-weight loss after 5 days,

$W_{o}$-initial weight,

$W_{f}$-final weight.

The standard expression for measurement of corrosion rate in mils per year (mpy) was used which is given as follows $[1,15]$.

$$
W=\frac{534 W}{D A T}
$$

where mpy—mils per year, $W$ - weight loss in mg, $D$ density of the materials in $\mathrm{g} / \mathrm{cc}, T$-time of exposure in hours, $A$-area in in ${ }^{2}$.

The inhibition efficiency was determined using the relationship [2,6]:

$$
\text { Inhibitor Efficiency }=\frac{W_{o}-W}{W_{o}} \times 100 \%
$$

where $W$ and $W_{o}$ are the corrosion rates with and without inhibitor respectively.

\section{Adsorption Consideration}

The degree of surface coverage, $O$ at each concentration of inhibitor was evaluated using the equation [16].

$$
O=1-\frac{W_{i}}{W_{b}}
$$

where $W_{b}$ and $W_{i}$ are the weight loss in corrodent without and with inhibitor respectively.

\section{Results and Discussions}

\subsection{Results}

The physiochemical screening of the bitter leaf extract revealed that the plant extract contained $0.9 \%$ tannin and 0.64\% Saponnin.

Figure 1 shows the variation of the corrosion rates with time of exposure for the reference and four different inhibitor concentrations in the $0.5 \mathrm{M} \mathrm{NaOH}$ solution. Figure 2 is the inhibition efficiency variation with time of exposure for different inhibitor concentrations in the caus- 
tic soda solution, while Figure 3 shows the degree of surface coverage with inhibitor concentration for the different time of exposure.

\subsection{Discussion of Results}

\subsubsection{Visual Observation of the Coupons}

Visual observation of the coupons in the solution with and without inhibitor after fifteen days (360 hours) of exposure revealed changes in color of the coupons from initial bright grayish surfaces to dull ones. Cracks and pits were observed on the coupons which are indication of severe corrosion attack by the alkaline media. Albeit, the change in color and presence of cracks were more noticed on the coupons in the solutions without inhibitor and with inhibitor of $0.2 \%$ and $0.3 \%$ concentration.

\subsubsection{Corrosion Rate and Inhibition Efficiency}

From the results obtained on the corrosion rate against exposure time at different inhibitor concentrations plotted in Figure 1; it is clear that corrosion rate increased with time for coupons in solution without inhibitor for the first ten days due to initial corrosion attack and subsequently decreased after fifteen days probably due to the deposition

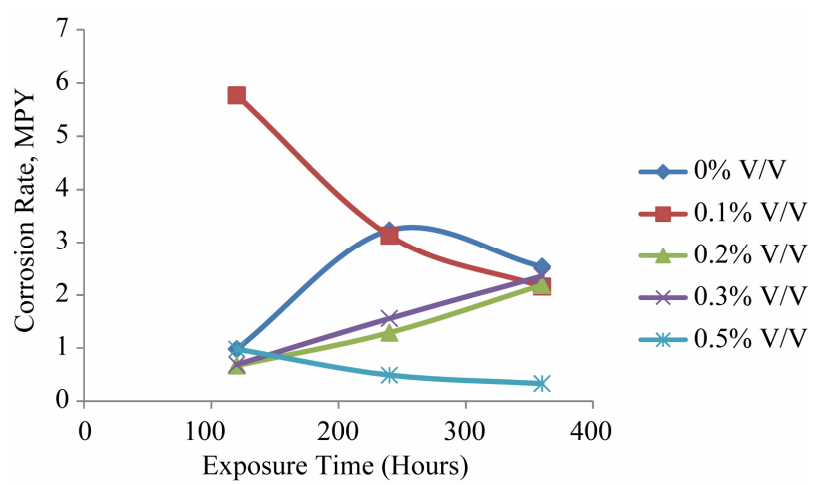

Figure 1. Variation of corrosion rate with time of exposure at different inhibitor concentrations.

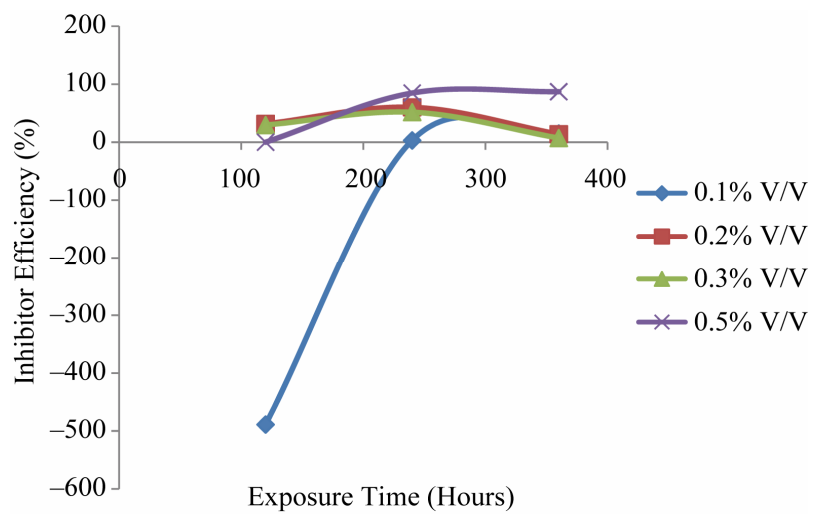

Figure 2. Variation of inhibition efficiency with time of exposure at different inhibitor concentrations.

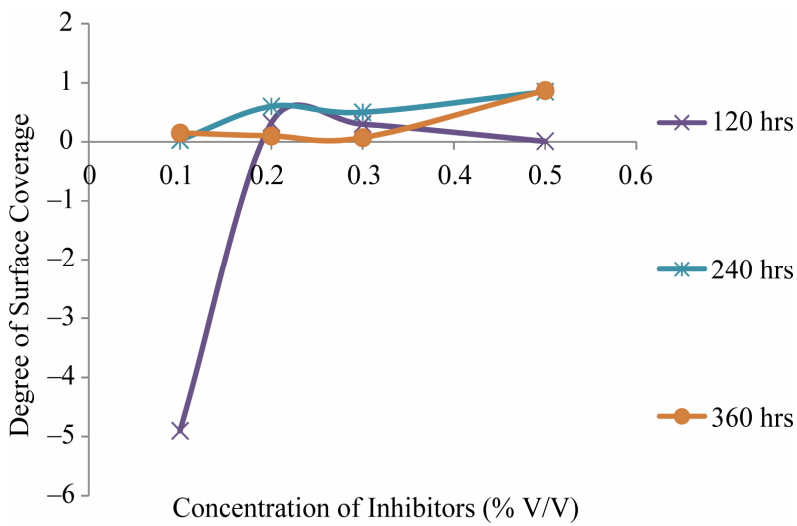

Figure 3. Variation of degree of surface coverage with different inhibitor concentrations at various times of exposure.

of corrosion products as the corrosion progresses which tends to shield the corroding surface from further corrosion attack, thereby depressing the rate of corrosion [1]. Corrosion also increased with time for coupons in $0.2 \%$ and $0.3 \%$ inhibitor concentration, this may mean that at these inhibitor concentrations, the protective bond of the inhibitor was broken down and the corrosion rate increased [2]. For $0.1 \%$ inhibitor concentration, the corrosion rate was higher than others after five days but decreased continuously for the rest of period of the experiment, this may be due to initial exposure of the coupons surface to attack and subsequent protection of same by the protective bond of the inhibitor for the remaining period of the experiment [17], while corrosion rate in the $0.5 \%$ inhibitor concentration decreased with time of exposure.

The significant decrease in corrosion rate at $0.5 \%$ inhibitor concentration can be attributed to the adsorption of molecule of the inhibitor on the alloy surface, since this inhibitor contains tannin which acts as physical barrier to restrict the diffusion of ions to and from the alloy and then prevent the alloy atoms (ions) from participating in further anodic or cathodic reactions, hence resulting in decrease in the corrosion rate [12]. The tannin in the plant extract can adsorb on the alloy surface and block the active sites on the surface, thereby reducing the corrosion rate in the medium.

From the plot of inhibition efficiency against exposure time (Figure 2), it can be seen that $0.5 \%$ inhibitor concentration has the highest protection efficiency and this increase with time of exposure, from $0 \%$ after five days to $84 \%$ after ten days and $87 \%$ after fifteen days. This shows that the inhibitor acts best after fifteen days at $0.5 \%$ inhibitor concentration.

The plot of the degree of surface coverage against inhibitor concentration (see Figure 3) revealed that 0.5\% inhibitor concentration has the highest protection efficiency since the highest degree of surface coverage by the inhibitor occurred at $0.5 \%$ inhibitor efficiency for fifteen 
days.

\section{Conclusions}

1) Bitter leaf extract (Vernonia amygdalina) decreases the corrosion of aluminium silicon alloy in $0.5 \mathrm{M} \mathrm{NaOH}$ solution subject to a level of $0.5 \%$ inhibitor concentration within fifteen days.

2) The mechanism of interaction between the inhibitor and the alloy is by physical adsorption. The adsorbed inhibitor molecules are attached at the alloy surface thereby blocking active corrosion sites hence lowering corrosion rate.

3) The inhibitor is recommended to be used at $0.5 \%$ concentration in $0.5 \mathrm{M} \mathrm{NaOH}$ and for a short period of time only.

\section{Acknowledgements}

The authors acknowledge with thanks the management of the National Metallurgical Development Centre for the equipment support and Mr. Polycarp Evarastic (Graduate Student, Ahmadu Bello University, Zaria, Nigeria) for the provision of the powdered plant extract and its chemical composition.

\section{REFERENCES}

[1] M. G. Fontana, “Corrosion Engineering,” 3rd Edition, McGraw-Hill Book Company, Boston, 1987, pp. 143-160.

[2] Y. I. Kuznetsov, "Physicochemical Aspects of Metal Corrosion Inhibition in Aqueous Solutions," Russian Chemical Reviews, Vol. 73, No. 1, 2004, pp. 75-87. doi:10.1070/RC2004v073n01ABEH000864

[3] E. E. Ebenso, "Corrosion Inhibition Studies of Some Plant Extracts on Aluminium in Acidic Medium," Materials Chemistry and Physics, Vol. 79, No. 1, 2003, pp. 58-62. doi:10.1016/S0254-0584(02)00446-7

[4] O. O. Adeyemi, "Effect of Temperature and Concentration on Protective Action of 5 Membered Heterocycles on Acid Corrosion of Brass," Journal of Correction Science and Technology, Vol. 3, No. 1, 2006, pp. 40-45.

[5] E. E. Oguize, B. N. Okolue, C. E. Ogukwe and A. I. Onuchukwu, "Studies on the Inhibitive Action of Methylene Blue Dye on Aluminium Corrosion in $\mathrm{KOH}$ Solution," Journal of Corrosion Science and Technology, Vol. 1, No. 1, 2004, pp. 88-91.

[6] A. Chetouani, B. Hanmouti and M. Benkaddour, "Corrosion Inhibition of Iron in Hydrochloric Acid Solution by

Jojoba Oil,” Pigment and Resin Technology, Vol. 33, No. 1, 2004, pp. 26-31. doi:10.1108/03699420410512077

[7] C. A. Loto and A. I. Muhammed, "The Effect of Cashew Juice Extract on the Corrosion Inhibition of Mild Steel in HCl," Corrosion Prevention and Control, Vol. 47, No. 2, 2005, pp. 13-22.

[8] P. C. Okafor, "Eco Friendly Corrosion Inhibitors: Inhibitive Action of Ethanol extracts of Garcinia Kola for the Corrosion of Mild Steel in $\mathrm{H}_{2} \mathrm{SO}_{4}$ Solution," Pigment Resin Technology, Vol. 36, No. 5, 2007, pp. 5-8. doi:10.1108/03699420710820414

[9] G. D. Davis, J. A. Fraunhofer, L. A. Krebs and C. M. Dacres, "The Use of Tobacco Extracts as Corrosion Inhibitor,” CORROSION 2001 Paper No. 58, NACE, Houston, 2001.

[10] C. A. Loto, "The Effect of Bitterleaf Extracts on Corrosion of Mild Steel in $0.5 \mathrm{M} \mathrm{HCl}$ and $\mathrm{H}_{2} \mathrm{SO}_{4}$ Solutions," Nigeria Corrosion Journal International, Vol. 1, 1998, pp 19-20.

[11] C. A. Loto, R. T. Loto and A. P. I. Popoola, "Effect of Neem Leaf (Azadirachita indica) Extract on the Corrosion Inhibition of Mild Steel in Dilute Acids,” International Journal of the Physical Sciences, Vol. 6, No. 9, 2011, pp. 2249-2257.

[12] C. A. Loto, "The Effect of Bitterleaf on the Inhibition of Mild Steel in $\mathrm{HCl}$ and $\mathrm{H}_{2} \mathrm{SO}_{4}$," Corrosion Prevention and Control Journal, Vol. 50, No. 1, 2003, pp. 43-49.

[13] G. O. Avwiri and F. O. Igho, "Inhibitive Action of Vernonia Amygdalina on the Corrosion of Aluminium Alloys in Acidic Media,” Materials Letters, Vol. 57, No. 22-23, 2003, pp. 3705-3711. doi:10.1016/S0167-577X(03)00167-8

[14] N. E. Idenyi and S. I. Neife, “The Corrosion Behaviour of Recrystallized Mild Steel in Various Tetraoxosulphate (VI) Acid Concentration,” Journal of Correction Science and Technology, Vol. 1, No. 1, 2004, pp. 9-16.

[15] F. A. Ayeni, V. S. Aigbodion and S. A. Yaro, "Non-Toxic Plant Extract as Corrosion Inhibitor for Chill Cast AlZn-Mg Alloy in Caustic Soda Solution,” Eurasian Chem Tech Journal, Vol. 9, No. 2, 2007, pp. 91-96.

[16] K. A. Olusegun, N. C. Oforka and E. E. Ebenso, “The Inhibition of Mild Steel Corrosion in an Acidic Medium by Fruit Juice of Citrus Paradisi,” Journal of Corrosion Science and Technology, Vol. 1, No. 2, 2004, pp. 75-78.

[17] E. E. Ebenso, U. J. Ekpe and S. Moren, "Corrosion Inhibition Studies of some Plant Extracts on Aluminium in an Acidic Medium using Carica Papaya and Azadiraachta Indica,” Journal of Corrosion Science and Technology, Vol. 1, No. 1, 2004, pp. 96-101. 